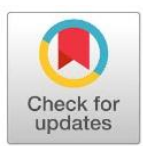

Received $04^{\text {th }}$ January 2020 Accepted $24^{\text {rd }}$ February 2020

www.ijpefs.com

\title{
Postural control in male ten-pin bowlers of different level of competitiveness
}

\author{
Vasilis Stefopoulos a, Katerina Iatridou a, Dimitris Karagiannakis a and \\ Dimitris Mandalidis a,*
a Sports Physical Therapy Laboratory, School of Physical Education and Sports Science, National and Kapodistrian University of Athens, Ethnikis Antistasis Str. 41, 172 37, Athens, Greece.
*Corresponding Author Email: dmndldis@phed.uoa.gr

\begin{abstract}
Ten-pin bowling is considered a highly skilled recreational activity with players demonstrating various anthropometric and physiological characteristics. The purpose of the current study was to assess both static and dynamic body balance, in ten-pin bowlers of different level of competitiveness. Thirty four ten-pin bowlers who competed at a high (Level-A, $n=17$ ) and a lower level (Level-B, $n=17$ ) as well as eighteen individuals without experience in ten-pin bowling (Non-bowlers) participated in the study. Static balance was determined based on the anteroposterior (APd) and mediolateral displacement (MLd) of the center-of-foot-pressure (CoP) that was recorded during single-leg-stance with open and close eyes as well as with open eyes and head extension. Dynamic balance was determined based on the APd and MLd of CoP as well as the normalized distances reached during execution of the Star Excursion Balance Test (SEBT) in the posterior, posterolateral and lateral directions. Significantly better dynamic balance, in terms of the distances reached during SEBT execution, was demonstrated by Level-A bowlers compared to Level-B bowlers and Non-bowlers. The differences between groups regarding APd and MLd, during both static and dynamic balance testing, were in general not significant. Our findings revealed that ten-pin bowlers who compete at a higher level demonstrate better dynamic balance ability. Sports scientists and coaches should be aware of these differences to optimize performance or distinguish ten-pin bowlers with different level of competitiveness.
\end{abstract}

Key Words: Recreational activity, Target sports, Athletic performance, Postural stability, Level of competitiveness

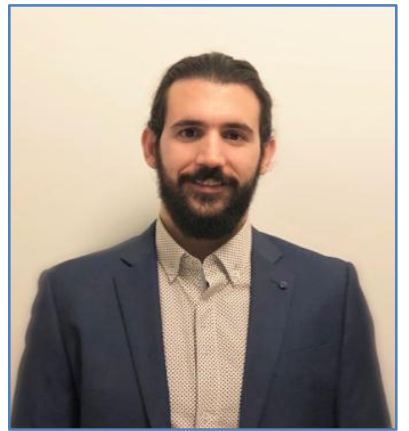

Mr.

Department

Educatio

Science

and

University of Athens,

Greece having specialized

in Fitness and Health. He

is a semi-professional ten-pin bowling athlete and as a member of the National ten-pin bowling team he won a second place in the 2015 European Championship. Currently he is working as a sales and a social media manager of a major Greek bowling centre constructor and he is involved in planning,
Stefopoulos organizing and managing ten-pin bowling from the tournaments. He also works as a trainer for novice and of Physical elite bowling players and coaches. His research and Sports interests are on aspects of ten-pin bowling the National performance and human postural control and Kapodistrian movement.

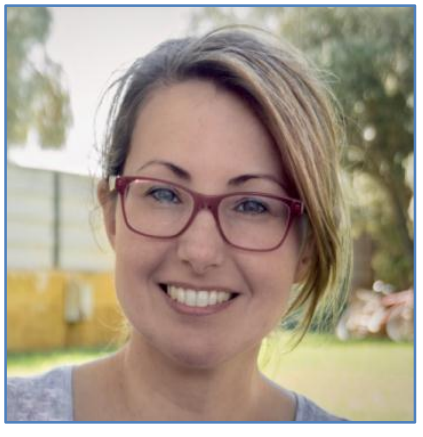

Ms. Iatridou studied Physical Therapy at the Department of Physical Therapy of the Technological Educational Institute (TEI) of Lamia of the University of Thessaly, Greece. In 2010 she 
received an MSc degree in Biology of Physical Activity, Institute (TEI), Athens. He has also awarded an MSc with specialty in Sport Medicine-Sport Physical degree in Sports Medicine and a PhD degree from Therapy and Rehabilitation, from the Department of Trinity College of the University of Dublin, Ireland. Physical Education and Sports Science of the National Currently he is working as an assistant professor at and Kapodistrian University of Athens, Greece. During the Department of Physical Education and Sports the academic years 2008-2012, she taught subjects Science of the National and Kapodistrian University of related to Sport Physical Therapy and Assessment and Athens where he is teaching Sport Physiotherapy, Rehabilitation of Musculoskeletal Dysfunctions in the Assessment and Rehabilitation of Musculoskeletal Laboratory of Sport Physical Therapy of the same University and currently she is conducting her doctorate studies in the field of Sport Rehabilitation. She also works as a self-employed physical therapist. Her scientific interests are in musculoskeletal assessment, therapeutic exercise in musculoskeletal dysfunctions and body balance disorders.

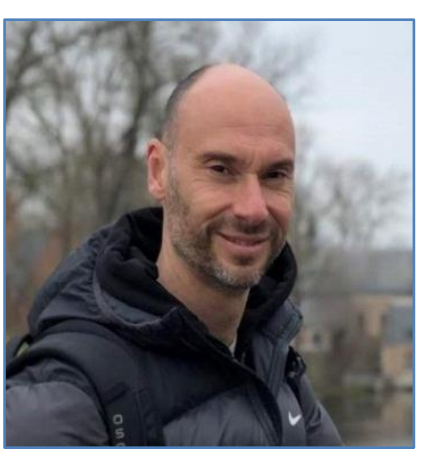

Mr. Karagiannakis graduated from the Department of Physical Education and Sports Science of the National and Kapodistrian University of Athens, Greece with specialty in Fitness and Health. In 2011, he received his Master's degree in Biology of Physical Activity, with specialty in Sport MedicineSport Physical Therapy and Rehabilitation, from the same Department. Currently he is working as a Parttime Lecturer of Physical Conditioning at Hellenic Air Force Academy and he is conducting his research studies in the field of Sport Rehabilitation for his doctorate degree at the National and Kapodistrian University of Athens. His research interests focus on sports performance, injuries prevention and rehabilitation

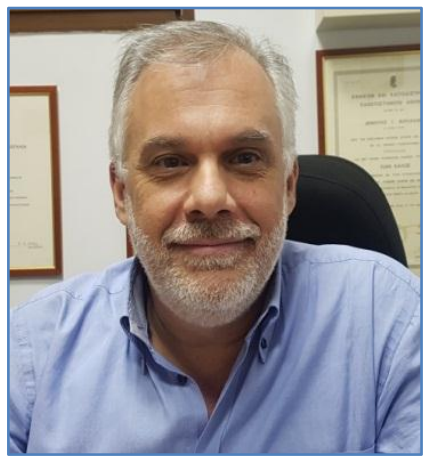

Dr. Mandalidis has received a BSc degree from the Department of Physical Education and Sports Science of the National and Kapodistrian University of Athens and a BSc degree from the Department of Physical Therapy of the Technological Educational
Dysfunctions and Therapeutic Exercise for Disorders of the Musculoskeletal System. He is the head of the Sports Physiotherapy Lab and the co-coordinator of the Sport Physical Therapy and Rehabilitation specialty of the Biology of Physical Activity postgraduate program that is offered by the same Department. His main research interests focus on musculoskeletal asymmetries, the effectiveness of exercise and assistive means in the human function and the postural control strategies during load transfer.

\section{Introduction}

Ten-pin bowling is one of the oldest and most popular recreational activities in the world with more than 100 million players in more than 141 countries worldwide. At a recreational and an amateur level it can be played by individuals of almost all age groups and of both genders with various anthropometric and physiological profiles. Competitive elite players, on the other hand, demonstrate specific anthropometric and physiological characteristics [1] as well as mental skills [2]. Elite players have longer lower leg and hand length as well as a wider arm span compared to non-bowlers [1]. Their bones are thicker in both upper (radius) and lower limbs (femur) [3] and they have greater forearm pronation and elbow flexion strength [1]. It has also been shown that aerobic capacity, as reflected by the aerobic power index, may contribute to a certain extend to bowling performance [4]. In terms of mental skills, skilled bowlers demonstrate also mental toughness, greater consistency, more interest in improvement, less use of luck of attributions, more confidence in equipment and technique and greater competitiveness. These characteristics enable today's player not only to compete successfully for 


\section{Vasilis Stefopoulos et al.,/2020}

long periods of time but to play at a high level until approximately 45 years of age presenting a decline in his/her bowling performance only less than $10 \%$ in a life span of 50 years $[5,6]$.

Considering the vast number of competitive ten-pin bowlers around the world and the variability in demographic (e.g. age, gender), physiological (e.g. strength, flexibility) and psychological characteristics (e.g. mental toughness) as well as playing forms (e.g. stroking, cranking) that they demonstrate, only few studies have investigated the differences of various parameters between genders [1, 6, 7], ways of bowling ball deliveries [6] and levels of competitiveness [2]. An ability that has not yet been investigated among ten-pin bowlers, even if it has a profound relationship with bowling performance, is body balance. Although it has been shown that accuracy of the front foot slide during the delivery phase seems less relevant compared to the accuracy of the ball release [8] its consistency and stability, particularly in terms of placement just before the foul line, is still of paramount importance. Optimal landing on the front foot following acceleration and braking is necessary to provide effective shock absorption and stability to the body and lower limb [9]. It may also ensure that maximum momentum of the hand will be passed on to the ball enabling the bowler to release the ball more effectively on the strike path [9].

The purpose of the current study, therefore, is to investigate body balance under both static and dynamic conditions in ten-pin bowlers of different level of competitiveness. Our findings may enable sports scientists and coaches to utilize body balance assessment in the identification process of potential highly skilful ten-pin bowlers and/or as a mean of performance enhancement.

\section{Method}

\subsection{Participant}

Static and dynamic body balance was assessed in 34 male ten-pin bowlers who were divided in two groups based on their level of competitiveness. Seventeen players with a mean score of $204.8 \pm 8.9$ pins/game classified as Level-A bowlers while 17 more players with a mean score $181.1 \pm 7.2$ pins/game classified as Level-B bowlers. The level of competitiveness was determined based on the average score that they achieved in national tournaments during the previous year. Eighteen individuals without experience in ten-pin bowling were selected for comparison. Information regarding their past/present medical health was selected prior to the investigation. Volunteers with (i) lower limb or spine pathologies and/or injuries that occur at least 3 months prior to participation in the study, (ii) neurologic, visual, vestibular, or balance disorders and (iii) those who participated in balance training programs were excluded from the study. The study protocol was approved by the University's Human Research Ethics Committee with all procedures performed in accordance with the ethical standards of the Helsinki Declaration, and each participant signed an informed written consent prior to testing.

\subsection{Static and dynamic balance assessment}

Static balance was determined based on the anteroposterior displacement (APd) and mediolateral displacement (MLd) of the center of foot pressure ( $\mathrm{CoP}$ ) that recorded during the singleleg-stance with open eyes (SLS-OE) and close eyes (SLS-CE) as well as with head extension and open eyes (SLS-HE) using a foot pressure distribution platform (FDMS, Zebris Co., Medical GmbH, Germany). The platform consisted of 1792 capacitive force sensors arranged in a $32 \times 56 \mathrm{~cm}$ matrix and it was synchronized to a personal computer. Foot pressure signals were recorded at sampling rate of $120-\mathrm{Hz}$ and analyzed with the WinFDMS software (WinFDMS 0.1 for Windows, Zebris Medical GmbH). Dynamic balance was determined by means of the APd and MLd of CoP as well as the distances reached in the posterior $(\mathrm{P})$, posterolateral (PL) and lateral (L) directions of the Star Excursion Balance Test (SEBT). In this case the foot pressure distribution platform was placed under a rectangular wooden frame, which was specifically structured in order to standardize the excursions in the three directions of SEBT (Figure 


\section{Vasilis Stefopoulos et al.,/2020}

1). An aluminum tube was fixed firmly on one of the shorts sides of the frame enabling reaching in $\mathrm{P}$ direction. An additional aluminum tube which was placed on the long side of the frame, enable us to position it at an angle of $45^{\circ}$ or $90^{\circ}$ relative to the posteriorly orientated tube, allowing reaching in PL and $\mathrm{L}$ direction, respectively. All tubes were marked in 1-mm increment.

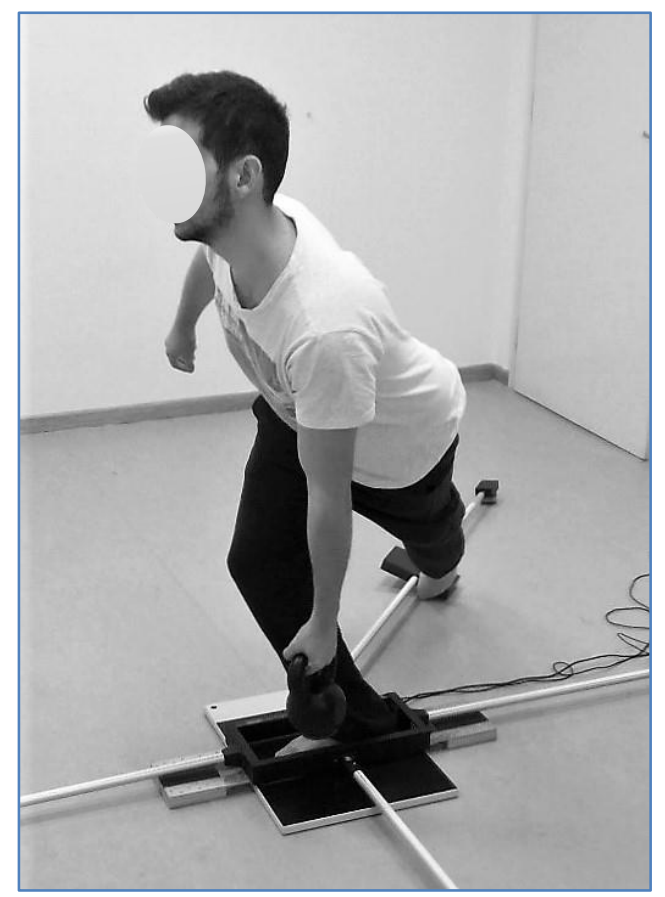

Figure 1. Left-handed A-Level bowler positioning for excursion in posterolateral direction.

\subsection{Testing procedure}

TEach participant reported to the laboratory for a single testing session during which SLS-OE, SLS-CE and SLS-HE were performed, followed by execution of SEBT in the P, PL and L direction. The static balance tests as well as the three directions of SEBT were performed in a randomized order. The lower limb that bowlers used for breaking before ball release (leading leg) was considered as the supportive one. The supportive lower limb in Nonbowlers was determined according to the Waterloo Footedness Questionnaire-Revised [10]. Execution of both static and dynamic body balance tests required each participant to remain as motionless as possible on the supportive lower limb for 10 seconds. For static balance testing each participant completed three practice trials for familiarization and three test trials with two minutes of recovery between trials to minimize fatigue. A test attempt was discarded if the participant removed his/her hands from the hips, placed the non-supportive lower limb on the ground, opened his/her eyes during SLS-CE test or lose postural control during the 10 seconds trial. Dynamic balance testing required each subject to stand with the leading or the supportive leg, for the bowlers and Non-bowlers respectively, on the center of the rectangular frame without wearing shoes and slide a rectangular reach indicator as far as possible, by touching it lightly with the free limb, along each one of the 2 tubes, which were orientated in the P, PL or L directions, for 10 seconds while holding a 5-kg kettlebell with the arm hanging freely and the elbow in full extension (Figure 1). Execution of dynamic balance testing in the aforementioned directions by holding the kettlebell was decided because it resembled more closely the position of the trail leg during the sliding step and the external forces, at least in part, that act on a ten-pin bowler before ball release. Participants completed three practice trials for familiarization and three test trials in each of the three directions with 2 minutes of recovery between each direction. After each trial the participants were instructed to return to the starting position, while maintaining balance. A test attempt was discarded if the participant removed his/her hands from the hips, failed to return to the starting position after reaching, raised the heel or moved the stance foot during the test, placed the reach foot on the ground and/or kicked or stand on the plate with the reaching foot to gain more distance. The average of the three trials for the CoP's APd and MLd that recorded during both static and dynamic body balance testing was calculated and used in the statistical analysis. The average of the three test trials of the distances reached in each one of the directions of SEBT was used in the statistical analysis after being normalized based on the length of the non-supportive lower limb [11].

\subsection{Statistical analysis}

Unpaired t-tests and one-way analysis of variance (ANOVA) was used to examine between 
groups differences regarding the demographic, anthropometric and sport-related training characteristics. Two-way ANOVA was used to examine the differences between the 3 groups of participants (Level-A bowlers, Level-B bowlers and Non-bowlers) at the three conditions of static (SLSOE, SLS-CE and SLS-HE) and dynamic body balance (SEBT-P, SEBT-PL and SEBT-L) testing for both APd and MLd of CoP as well as for the normalized reaching distances achieved during SEBT's directions. Significant main effects were followed by pairwise comparisons after a Bonferroni adjustment for controlling Type I error. Statistical analysis was conducted in SPSS, version 25.0 (IBM Corp, Armonk, NY, USA).

\section{Results}

The differences between groups regarding the demographic and anthropometric characteristics were not significant. Level-A bowlers achieved significant greater scores $(\mathrm{p}<0.001)$ and displayed greater training frequency per week $(\mathrm{p}<0.05)$ compared to Level-B bowlers. The differences between Level-A and Level-B bowlers regarding the number of years active, the ratio of participants' biological age/years active and the number of hours practicing bowling per session were not significant (Table 1 ).
Data analysis revealed significant differences between groups regarding MLd $(\mathrm{p}<0.05)$ and APd of CoP $(p<0.001)$ only during SEBT execution. Significant were also the differences between the conditions tested during SLS and between the directions reached during SEBT for both MLd ( $p<0.001$ and $p<0.05$ respectively) and APd of CoP $(p<0.001)$. Non-significant were the interactions between the level of competitiveness and the condition tested during SLS as well as during SEBT excursions (pairwise comparisons are presented in Table 2).

Significant main effects were obtained between groups $(\mathrm{p}<0.001)$ and between the SEBT's excursions $(\mathrm{p}<0.001)$ for the normalized distances reached by ten-pin bowlers and Non-bowlers. Pairwise comparisons revealed that Level-A bowlers achieved longer distances compared to Level-B bowlers in $P(\mathrm{p}<0.05)$ and PL $(\mathrm{p}<0.01)$ directions as well as compared to Non-bowlers in $\mathrm{P}$ $(p<0.01)$. PL $(p<0.001)$ and $L$ directions $(p<0.05)$. The differences between Level-B bowlers and Nonbowlers with regard to the distances reached in all direction were not significant. Pairwise comparisons revealed also significant differences between $\mathrm{P}$ and $\mathrm{L}$ direction $(\mathrm{p}<0.001)$ as well as between PL and L direction $(p<0.001)$ with regard to the reaching distances in all groups of bowlers (Figure 2).

Table 1 Means (standard deviations) of demographic, anthropometric and sport-related training characteristics of the study samples

\begin{tabular}{lrlrlcc}
\hline & \multicolumn{2}{c}{$\begin{array}{c}\text { Level-A bowlers } \\
(\mathrm{n}=17)\end{array}$} & \multicolumn{2}{c}{$\begin{array}{c}\text { Level -B bowlers } \\
(\mathrm{n}=17)\end{array}$} & \multicolumn{2}{c}{$\begin{array}{c}\text { Non-bowlers } \\
(\mathrm{n}=18)\end{array}$} \\
\hline Age (yrs) & 32.0 & $(8.9)$ & 32.6 & $(9.1)$ & 32.3 & $(7.3)$ \\
Height $(\mathrm{cm})$ & 178.7 & $(5.2)$ & 178.4 & $(5.9)$ & 181.1 & $(6.5)$ \\
Weight $(\mathrm{kg})$ & 83.2 & $(10.8)$ & 88.1 & $(20.1)$ & 88.3 & $(4.1)$ \\
BMI & 26.0 & $(3.1)$ & 27.5 & $(5.2)$ & 26.8 & $(3.4)$ \\
Score (pins) & 204.8 & $(8.9)$ & 181.1 & $(7.2)^{\mathrm{a}}$ & - & - \\
Years active & 12 & $(4.2)$ & 10.2 & $(4.7)$ & - & - \\
Age/Years active & 0.4 & $(0.1)$ & 0.3 & $(0.1)$ & - & - \\
Training sessions/week (n) & 3.4 & $(1.0)$ & 2.7 & $(0.5)^{\mathrm{b}}$ & - & - \\
Hours practice/session (hr) & 2.3 & $(0.4)$ & 2.4 & $(0.6)$ & - & - \\
\hline
\end{tabular}

a significant different compared to Level-A bowlers $(\mathrm{p}<0.001)$

b significant different compared to Level-A bowlers $(\mathrm{p}<0.05)$ 


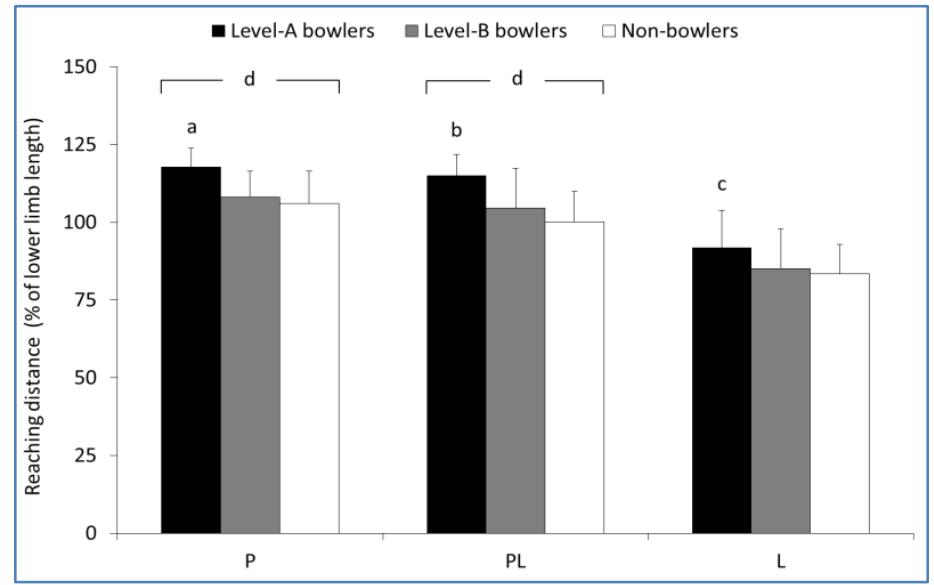

Figure 2 Mean and standard deviations (error bars) of the distances reached by Level-A and Level-B bowlers as well as Non-bowlers during execution of the Star Excursion Balance Test in the posterior $(\mathrm{P})$, posterolateral (PL) and lateral (L) directions.

a Significant greater compared to Level-B bowlers $(\mathrm{p}<0.05)$ and Non-bowlers $(\mathrm{p}<0.01)$

b Significant greater compared to Level-B bowlers $(p<0.01)$ and Non-bowlers $(p<0.001)$

c Significant greater compared to Non-bowlers $(\mathrm{p}<0.05)$

d Significant greater compared to L-direction $(\mathrm{p}<0.001)$

Table 2 Means (standard deviations) of anteroposterior and mediolateral displacements (APd, MLd) of the centre of pressure (CoP) during single-leg-stance with open eyes (SLS-OE), closed eyes (SLS-CE) and head extension with open eyes (SLS-HE) as well as during execution of Star Excursion Balance Test in the posterior (SEBT-P), posterolateral (SEBT-PL) and lateral directions (SEBT-L).

\begin{tabular}{|c|c|c|c|c|}
\hline $\begin{array}{l}\text { Balance } \\
\text { condition }\end{array}$ & $\begin{array}{c}\text { Direction of CoP } \\
\text { displacement }\end{array}$ & $\begin{array}{l}\text { Level-A bowlers } \\
\qquad(\mathrm{n}=17)\end{array}$ & $\begin{array}{l}\text { Level-B bowlers } \\
\qquad(\mathrm{n}=17)\end{array}$ & $\begin{array}{c}\text { Non-bowlers } \\
(\mathrm{n}=18)\end{array}$ \\
\hline \multirow[t]{2}{*}{ SLS-OE } & APd & $\begin{array}{ll}6.7 & (1.4)\end{array}$ & $\begin{array}{ll}6.8 \quad(1.5) \\
\end{array}$ & $(1.7)$ \\
\hline & MLd & $4.8 \quad(1.0)$ & $5.7 \quad(1.2)$ & $5.1 \quad(1.5)$ \\
\hline \multirow[t]{2}{*}{ SLS-CE } & APd & $13.4 \quad(2.4)$ & $(3.0)$ & $(3.0)$ \\
\hline & MLd & 12.1 & $(1.6)$ & $(2.5)$ \\
\hline \multirow[t]{2}{*}{ SLS-HE } & APd & $9.5 \quad(3.5)$ & $(2.5)$ & $(2.6)$ \\
\hline & MLd & $5.6 \quad(1.3)$ & $(1.1)$ & $(1.2)$ \\
\hline \multirow[t]{2}{*}{ SEBT-P } & APd & $16.7 \quad(4.7)$ & $(3.1)^{\mathrm{a}}$ & $(6.6)$ \\
\hline & MLd & $7.1 \quad(1.0)$ & $(0.7)$ & (1.4) \\
\hline \multirow[t]{2}{*}{ SEBT-PL } & APd & $12.1 \quad(2.8)$ & $(2.2)$ & $(3.6)$ \\
\hline & MLd & $6.7 \quad(1.2)$ & $(1.2)$ & $7.6 \quad(2.1)$ \\
\hline \multirow[t]{2}{*}{ SEBT-L } & $\mathrm{APd}$ & $12.8 \quad(2.9)$ & $(2.8)$ & $(1.9)^{b}$ \\
\hline & MLd & $7.3 \quad(1.2)$ & $(2.1)$ & (1.7) \\
\hline
\end{tabular}

a Significant lower compared to Level-A bowlers $(\mathrm{p}<0.01)$ and Non-Bowlers $(\mathrm{p}<0.05)$

b Significant lower compared to Level-A bowlers $(\mathrm{p}<0.05)$ 


\section{Vasilis Stefopoulos et al.,/2020}

\section{Discussion}

The purpose of this study was to investigate whether body balance requirements were differentiated among ten-pin bowlers of different level of competitiveness. Our findings revealed that only dynamic balance, based on the distance reached during execution of SEBT in the P and PL direction, was superior in ten-pin bowlers with a higher level of competitiveness compared to their counterparts with a lower level of competitiveness and to Nonbowlers. Furthermore, dynamic balance was similar between bowlers with a lower level of competitiveness and Non-bowlers. The fact that athletes with different levels of competitiveness demonstrated different levels of dynamic, but not static, body balance may be explained by the tests used to measure body balance ability. It has been suggested that the closer body balance is assessed to a sport-related task or condition the more a test may be able to detect differences between athletes with different levels of competitiveness [12]. Experienced shooters have demonstrated better postural stability when they were measured close to the firing of the shot compared to naïve shooters [13, 14] and international level surfers demonstrated better postural control than regional level surfers, only when they were measured on an unstable surface [15]. Postural stability under dynamic conditions was assessed in our study with SEBT, a test that resembled to a great extend bowling lunge, as the stabilizing lower limb was squatting while the contralateral lower limb reached in the P, PL or L directions. Hence, it was not surprising that SEBT, enabled us to detect more easily differences regarding dynamic balance between bowlers with different level of competitiveness and Non-bowlers.

The longer distances that were achieved by Level-A compared to Level-B bowlers may be attributed to their ability to lower more their body's centre of mass, by bending the joints and stretching the muscles of the supporting lower limb more efficiently during reaching, despite some evidences that support otherwise. Tan et al. [6] have suggested that the contribution of muscles' flexibility to bowling performance is doubtful but probably only because the assessment of flexibility in their study was performed with an inappropriate test. Flexibility in their study was assessed with the sit and reach, a test that requires flexible hip extensors (e.g. hamstrings) and paravertebral muscles, that is muscle groups that are hardly stretched throughout the bowling approach [6]. Endo and Sakamoto [16] in a more recent study failed also to show any relationship between SEBT execution in P direction and iliopsoas, quadriceps, hamstring, gastrocnemius, as well as hip internal and external rotator tightness in male junior high school baseball players. Other authors have shown that SEBT performance in the PL direction was not related with dorsi-flexion range of motion [17]. Findings from previous studies, on the other hand, which have investigated lungerelated sport performance such as in fencing and curling [18], could justify to a certain extend our observations. It has been shown that the magnitude of peak range of hip flexion of the leading leg is a significant indicator of weapon velocities during lunge performance in experienced fencers [19] and probably one of the factors that differentiate them from novice fencers [20]. Yoo, Kim, and Park [21] have also shown that the superior ability of elite curlers to maintain a regulated balance control and movement speed during the delivery of a curling stone depends on larger ankle dorsiflexion, as well as greater contact area of the sliding foot, compared to sub-elite curlers. The same authors reported also that elite curlers demonstrated non-significant greater hip and knee ranges of motion compared to sub-elite curlers [21]. Eventually, lowering the body may be advantageous to highly proficient bowlers as it may enable them to release the ball more effectively by passing to it the maximum momentum developed by the upper limb during ball delivery.

Our findings also revealed that both APd and MLd of CoP that were measured under static balance conditions could not distinguish balance ability between ten-pin bowlers with different level of competitiveness or bowlers from Non-bowlers. The displacement of CoP has been used by several authors in quantifying postural control under static conditions. However, the evidence reported in the literature regarding balance ability between elite athletes and less proficient counterparts are conflicting. Bipedal or unipedal static balance has 


\section{Vasilis Stefopoulos et al.,/2020}

been found to be better in experienced and international level shooters compared to less experienced or national level shooters respectively $[13,22]$, professional or national level soccer players compared to amateur or regional level soccer players [23, 24] and most proficient golfers compared to less proficient golfers [4]. In agreement to our findings static balance has been found to be similar between National or International and regional alpine skiers [25] and judoist [26] as well as between elite and intermediate level surfers [27]. The inability to detect differences based on the displacements of CoP may lie in the fact that postural stability was not challenged enough to exacerbate CoP movements under static conditions. The movement of CoP is highly depended on movements of the center of gravity and the projection of the muscle forces that are required to control or produce the movements. Ultimately, the displacements of CoP remained unaffected not only under unipedal static balance testing conditions but also under dynamic testing conditions even though the latter required a considerable forward lean of the trunk and a significant amount of muscle force production to maintain postural stability. Possibly, the great activation that is displayed by the ankle's musculature during reaching in the $\mathrm{P}, \mathrm{PL}$ and $\mathrm{L}$ directions of SEBT may provide better stability preventing excessive displacements of CoP under these dynamic balance conditions [28].

\subsection{Limitations}

Balance ability in the current study was investigated without controlling for the participants' gender and bowling form and therefore our findings could be extrapolated to the population of ten pin-bowlers only by considering these limitations. The sample in our study included only male ten-pin bowlers, mainly because the sport at national level is dominated by them. However, female ten-pin bowlers may have performed better during SEBT as, according to some authors, they demonstrate better dynamic postural control than males [29]. This has been manifested during SEBT execution by achieving longer normalized reaching distances in the posterior as well as in the anterior direction compared to males demonstrating at the same time a greater amount of knee flexion [29].

Additionally, the bowling form was not controlled because bowlers during their career, particularly those who are play at a higher level, develop their own unique styles which are very effective for each player [30]. Different styles may require different balance abilities as they vary in many ways such as in upper limb and body momentum, foot placement and ball releasing techniques. Ultimately, our findings could also be affected by the highest training volume that witnessed by high-level bowling players compared to lower-level bowling players. This resulted from the fact that although Level-A and Level-B players were practicing almost the same amount of time per training session, the former were trained 0.7 times/week more than the latter. Whether the superior dynamic balance ability that demonstrated by Level-A bowlers was the result of the greater training volume cannot be justified in the present study. The unequal level of physical activity between athletes with different levels of competitiveness has been posed as a potential threat to the validity of the conclusions that were drawn from similar studies [31]. Future studies should consider participants' gender and bowling form as well as equality of physical activity volume when sport or activity-related ability is investigated between groups.

\section{Conclusions}

The findings of the present study revealed that, based on the normalized reaching distances during SEBT execution in the P, PL and L direction, playing ten-pin bowling at a higher-level require better dynamic balance ability as opposed to playing at a lower-level. Coaches therefore could implement dynamic balance ability testing for distinguishing different levels of competitiveness among ten-pin bowlers and players could incorporate exercise to their training programs in order to improve their performance. Ten-pin bowling, should also be considered as a non-highly demanded activity, at least in terms of body balance, 


\section{Vasilis Stefopoulos et al.,/2020}

when it is performed at a less competitive level and therefore could be a potential recreational activity either for less skilful or even unrelated to bowling individuals.

\section{References}

[1] Razman R, Cheong JPG, Wan Abas WAB, Abu Osman NA. Anthropometric and strength characteristics of tenpin bowlers with different playing abilities. Biology of Sport. 2012;29(1):33-8.

[2] P.R. Thomas, P.J. Schlinker, R. Over, Psychological and psychomotor skills associated with prowess at ten-pin bowling, Journal of Sports Sciences, 14 (1996) 255-268.

[3] K.C. Young, V.D. Sherk, D.A. Bemben, Inter-limb musculoskeletal differences in competitive tenpin bowlers: A preliminary analysis, Journal of Musculoskeletal and Neuronal Interactions, 11 (2011) 21-26.

[4] T.C. Sell, Y.S. Tsai, J.M. Smoliga, J.B. Myers, S.M. Lephart, Strength, flexibility, and balance characteristics of highly proficient golfers, Journal of Strength and Conditioning Research, 21 (2007) 1166-1171.

[5] A.E. Devan, H. Tanaka, Declines in ten-pin bowling performance with advancing age, Age Ageing, 36 (2007) 693-694.

[6] B. Tan, A. Rashid Aziz, T. Kong Chuan, Correlations between physiological parameters and performance in elite ten-pin bowlers, Journal of Science and Medicine in Sport, 3 (2000) 176-185.

[7] D.P.K. Chu, B. Zhang, K. Mau, Ten-pin bowling technique on elite players. In: Gianikellis KE, editor. 20 $0^{\text {th }}$ International Symposium on Biomechanics in Sports, 2002. p. 123-5.

[8] R. Razman, W.A.B. Wan Abas, N.A.A. Othman, Front foot slide variability and its relation to ten-pin bowling performance. In: R. Jensen, W. Ebben, E. Petushek, C.R.K. Richter, editor. Proceedings of the 28th International Conference on Biomechanics in Sports. Michigan, USA; 2010. p. 759-60.

[9] R. Vasiljev, A. Vasiljev, S. Milosavljevic, An exploration of center of pressure under the delivery leg during nine-pin bowling, Footwear Science, 7(Suppl.1) (2015) S8-S10.

[10] L.J. Elias, M.P. Bryden, M.B. Bulman-Fleming, Footedness is a better predictor than is handedness of emotional lateralization, Neuropsychologia, 36 (1998) 37-43.

[11] P.A. Gribble, J. Hertel, Considerations for normalizing measures of the Star Excursion Balance Test, Measurement in Physical Education and Exercise Science, 7 (2003) 89100.

[12] C. Hrysomallis, Balance ability and athletic performance, Sport Medicine, 41 (2011) 221232.

[13] P. Era, N. Konttinen, P. Mehto, P. Saarela, H. Lyytinen, Postural stability and skilled performance-A study on top-level and naive rifle shooters, Journal of Biomechanics, 29 (1996) 301-306.

[14] J. Larue, C. Bard, L. Otis, M. Fleury, Stability in shooting: the effect of expertise in the biathlon and in rifle shooting, Canadian Journal of Sport Sciences, 14 (1989) 38-45.

[15] T. Paillard, E. Margnes, M. Portet, A. Breucq, Postural ability reflects the athletic skill level of surfers, European Journal of Applied Physiology, 111 (2011) 1619-1623.

[16] Y. Endo, M. Sakamoto, Relationship between lower extremity tightness and Star Excursion Balance Test performance in junior high school baseball players, Journal of Physical Therapy Science, 26 (2014) 661-663.

[17] M.C. Hoch, G.S. Staton, P.O. McKeon, Dorsiflexion range of motion significantly influences dynamic balance, Journal of Science and Medicine in Sport, 14 (2011) 90-92.

[18] D.G. Behm, Periodized training program of the Canadian olympic curling team. Strength \& Conditioning Journal, 29 (2007) 24-31.

[19] L. Bottoms, A. Greenhalgh, J. Sinclair, Kinematic determinants of weapon velocity during the fencing lunge in experienced épée fencers, Acta of Bioengineering and Biomechanics, 15 (2013) 109-13.

[20] T.L.W. Chen, D.W.C. Wong, Y. Wang, S. Ren, F. Yan, M. Zhang, Biomechanics of fencing sport: A scoping review, PLoS One, 12 (2017). 
[21] K.S. Yoo, H.K. Kim, J.H. Park, A biomechanical assessment of the sliding motion of curling delivery in elite and subelite curlers, Journal of Applied Biomechanics, 28 (2012) 694-700.

[22] V. Niinimaa, T. McAvoy, Influence of exercise on body sway in the standing rifle shooting position, Canadian Journal of Applied Sport Sciences, 8 (1983) 30-33.

[23] T. Paillard, F. Noé, Effect of expertise and visual contribution on postural control in socce, Scandinavian Journal of Medicine \& Science in Sports, 16 (2006) 345-348.

[24] T. Paillard, F. Noé, T. Rivière, V. Marion, R. Montoya, P. Dupui, Postural performance and strategy in the unipedal stance of soccer players at different levels of competition, Journal of Athletic Training, 41 (2006) 172176.

[25] F. Noé, T. Paillard, Is postural control affected by expertise in alpine skiing? British Journal of Sports Medicine, 39 (2005) 835-837.

[26] T. Paillard, C. Costes-Salon, C. Lafont, P. Dupui, Are there differences in postural regulation according to the level of competition in judoists?, British Journal of Sports Medicine, 36 (2002) 304-305.
[27] D.W. Chapman, K.J. Needham, G.T. Allison, B. Lay, D.J. Edwards, Effects of experience in a dynamic environment on postural control, British Journal of Sports Medicine, 42 (2008) 16-21.

[28] D. Karagiannakis, K. Iatridou, S. Athanasopoulos, D. Mandalidis, Postural control during Star Excursion Balance Test. In: A. Radmann, S. Hedenborg, E. Tsolakidis, editors. Book of Abstracts of the 20th Annual Congress of the European College of Sport Science, Malmö; 2015. p. 220.

[29] P.A. Gribble, R.H. Robinson, J. Hertel, C.R. Denegar, The effects of gender and fatigue on dynamic postural control, Journal of Sport Rehabilitation, 18 (2009) 240-257.

[30] Borden F. Bowling: Knowledge is the Key. Elite Bowling Corp; 1986.

[31] H. Kiers, J. Van Dieën, H. Dekkers, H. Wittink, L. Vanhees, A systematic review of the relationship between physical activities in sports or daily life and postural sway in upright stance, Sport Medicine, 43 (2013) 1171-1189.

\section{Funding}

This study was not funded by any grant

\section{Conflict of interest}

None of the authors have any conflicts of interest to declare.

\section{Informed consent}

All participants gave written informed consent to participate in this study.

\section{About The License}

\section{() (7)}

Attribution 4.0 International (CC BY 4.0)

Attribution 4.0 International License 